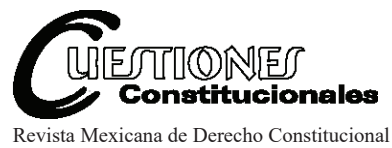

Núm. 38, enero-junio 2018

\title{
SISTEMAS DE GOBIERNO EN AMÉRICA LATINA. EL CASO CHILENO
}

\section{GOVERNMENT SYSTEMS IN LATIN AMERICA. THE CHILEAN CASE}

\begin{abstract}
Resumen: Desde la perspectiva de la sociología jurídica, este artículo problematiza y analiza el problema de las formas de gobierno y de la estructura del orden social, así como de las paradojas operativas en la cual estas formas se estabilizan. Es decir, analiza el tipo de esquemas que se han institucionalizado para organizar la "inclusión" operativa en la vida política y en los procesos de toma de decisiones, particularmente en el caso chileno posterior a la dictadura militar.
\end{abstract}

Palabras clave: diferenciación, sistema político, derecho, democracia, ciudadanía.

\section{Raúl Zamor ano Far ías*}

ABSTRACT: From the perspective of legal sociology, this article problematizes and analyzes the problem of the forms of government and the structure of social orden, as well as operational paradoxes in which these forms are stabilized. That is, analyzes the type of schemes that have been institutionalized to organize the "inclusion" operating in political life and in decision-making processes, particularly in the case of Chile, following the military dictatorship.

Keywords: Differentiation, Political System, Law, Democracy, Citizenship.

* Centro de Estudios Teóricos y Multidisciplinarios en Ciencias Sociales, UNAM. Correo electrónico rzamorano61@gmail.com. 
Esta revista forma parte del acervo de la Biblioteca Jurídica Virtual del Instituto de Investigaciones Jurídicas de la UNAM

Sumar io: I. Introducción. II. Régimen político y formas jurídicas en la región. III. El caso chileno. IV. Epítome. V. Bibliografía.

\section{Int roduc ción}

La ley se acata pero no se cumple...

Históricamente, en América Latina el script de la cultura política tiene una impronta de carácter patrimonial. ${ }^{1}$ Aun cuando este esquema ha estado en permanente "reforma" no ha sido sustancialmente modificado por los presupuestos de la modernidad y por las expectativas que reconoce la democracia. $^{2}$

Como señala Wolf, en las sociedades "patrimoniales" se articulan mecanismos que bloquean sus capacidades transformadoras. Este tipo de sociedades presentan una ausencia de diferenciación estructural entre centro y periferia y un alto grado de exclusión y segregación, así como escasa articulación simbólica de vinculación política. ${ }^{3}$ Precisamente, una de las

1 Si la democracia no es un en sí mismo, sino un medio para establecer una tabla axiológica de valores y expectativas (Weber, Max, La sociología del derecho, México, UNAM, 1989) que se constituyen en fuentes de inspiración y sentido de la democracia moderna (isonomía: igualdad ante la ley; isegoría: igualdad en el uso de la palabra y koinonía: comunidad de cooperación para alcanzar el bien público), cómo operan entonces las estrategias de repartición de las ventajas y las expectativas de futuro cuando el orden social está orientado/determinado por el trá o de in encias y por la preminencia de redes patrimoniales y clientelares. Wolf, Erick, Peasent Wars of the Twentieth Century, Nueva York, Harper and Row, 1969; Luhmann, Niklas, Cómo es posible el orden social, México, Herder Editores, 2010.

2 Lo anterior se puede observar a través del análisis de teorías en oposición, como son la dependencia y la modernización (décadas del cincuenta y sesenta del siglo XX). Cada sociedad, en cualquiera de estas versiones, contaba con un sujeto privilegiado portador del proyecto histórico de la sociedad. Los actores eran, así, actores de un libreto que estaba escrito, y no sujetos creadores de su acción, por lo que el análisis tendía a concentrarse en los obstáculos o "desviaciones" de la evolución pre ada. En este contexto, la política era la aplicación voluntarista de las teorías (o ideologías) "correctas" a la historia concreta. Esto fue así para el marxismo, el funcionalismo y todas las "grandes" teorías que circularon hasta los años setenta y que todavía circulan como oferta no sólo teórica.

3 Wolf, Erick, Peasent Wars..., cit., pp. 160, 161, 274 y 275. 
constantes históricas del patrimonialismo es la preminencia del centralismo político (como vértice de la estructura de la sociedad), en busca de la representación de la unidad del todo social y cuya mayor expresión se funda en el asistencialismo estatal centralizado, bajo la egida del Ejecutivo. ${ }^{4}$

En tal sentido, observamos que gran parte de aquellos presupuestos que orientan la participación y organización política (y la expectativa democrática moderna), ha devenido una desnuda formalidad que se reduce, casi siempre, a la opción de depositar el voto, haciendo ilusorio suponer que con la imposición de la democracia procedimental o con las así llamadas transiciones democráticas, estas prácticas han cambiado. De modo que, en la región latinoamericana, las expectativas "democráticas" y su acoplamiento con el sistema político terminan por consolidar la reoligarquización de la política (castas), la fragilidad institucional, el homo mediático y el neocorporativismo clientelar. ${ }^{5}$

Además, si el acoplamiento entre política y otros sistemas parciales presupone establecer a través de crecientes procesos de

estructuras que hagan plausible la civilización del poder, ${ }^{6}$ en la región observamos que se ha estabilizado un modelo de acoplamiento que parece más bien fagocitar mecanismos que, cuanto más amplía las redes de participación, tanto más es obligado a incluir en su interior redes de que expanden y alimentan la incerteza operativa del sistema político y del derecho, así como de sus siempre precarios niveles de cuya consecuencia más evidente es la reoligarquización del quehacer político, el achicamiento de la ciudadanía y la estabilización de la corrupción como esquema cultural de orientación. Al respecto, no se puede obliterar la "importancia" que ha tenido en este contexto la evolución del sistema de derecho y su forma para operar: la ley se acata pero no se cumple.

4 Luhmann, Niklas, La sociedad de la sociedad, México, Herder-Universidad Iberoamericana Editores, 2007; id., Cómo es posible..., cit.

5 Sobre esto véase O’Donnell, Guillermo, Contrapuntos, Barcelona, Paidós, 1997, pp. 260-269; Zapata, Francisco, Ideología y política en América Latina, México, COLMEX, 1990. No se trata de volver al bizantino problema del deber ser o el qué es la democracia, sino el cómo es posible. Obviamente, se trata de observar cómo las operaciones y efectos de diversos sistemas funcionales se combinan, ampli an y estorban, en razón de condiciones que sólo se presentan regionalmente y que, por consiguiente, producen modelos muy distintos. Luhmann, Niklas, La sociedad de la sociedad, cit., p. 640.

6 Willke, Helmut, Systemtheorie Entwickelter. Gesellschaften Dynamik und Riskanz moderner gesellschaftlicher Selbstorganisation, Deutschland, Juventa Verlag-Weinheim/ München, 1993; Luhmann, Niklas, La sociedad de la sociedad, cit. 
En la práctica, las expectativas promovidas por la reinstitucionalización democrática (Argentina, Brasil, Chile, Uruguay) y la "caída" de los regímenes autoritarios (Colombia, México) han resultado el acíbar más fuerte para la inmensa mayoría de la población. El resultado de todo esto es que los derechos (políticos y sociales) conquistados históricamente, han sido transformados en servicios a paga y los ciudadanos en consumidores para una democracia de espectadores. ${ }^{7}$

No resulta entonces ingenuo sostener que, en general, la experiencia política, constitucional, jurídica y democrática en el continente ha sido todo un éxito en el plano teórico pero un profundo fracaso en la práctica: en su efectividad. Piénsese en los casos particulares de países como Brasil, Paraguay, México, Venezuela o Chile, país este último en donde el contenedor normativo constitucional de la nación que orienta el sistema de gobierno se rige en la actualidad por la Constitución de 1980, creada y diseñada por la dictadura militar. ${ }^{8}$

Precisamente, en la actualidad y con la reinstalación del problema de las formas de gobierno y "democracia", es donde se puede observar la diferencia funcional del sistema y régimen político en las sociedades de Latinoamérica, así como las paradojas operativas en sus formas de producir orden social. ${ }^{9}$

\section{Régimen político y formas jurídicas en la región}

La pregunta es quién ejerce el poder y en beneficio de quién. ${ }^{10}$

El régimen político denota al conjunto de instituciones que regulan la lucha y el ejercicio del poder, así como de los valores que orientan las estructuras de gobierno y la organización del sistema político. ${ }^{11}$

7 Zamorano Farías, Raúl, Entre la teoría y la acción. Dilemas sobre la acción colectiva popular Santiago de Chile: 1988-1992, México, Juan Pablos Editor, 2001.

8 Zamorano Farías, Raúl, "Logiche di inclusione-esclusione politica nella società moderna (come la legge si rispetta, ma non obbedi)", Rivista Teoria del Diritto e dello Stato 3, Turín, Giappichelli Editore, 2003.

9 En relación con las posibilidades del cómo del orden social Luhmann, Niklas, Teoría politica en Estado de bienestar, Madrid, Alianza, 1993; id., La sociedad de..., cit.; id., Cómo es posible..., cit.; Habermas, Jürgen, Crisis de legitimación en el capitalismo tardio, Buenos Aires, Amorrortu, 1985.

10 Schmitt, Carl, Teoría de la Constitución, México, Nacional, 1981.

11 En nuestra región, el "presupuesto" que orienta la estructuración y regulación de las relaciones de poder, así como las formas orgánicas de gobierno, se fundamenta en el 
En América Latina la estructuración del régimen político pude rastrearse en los albores de las luchas de independencia. Recordemos que en la región hispana, las elites tradicionales, herederas en su mayoría del imperialismo colonialista y del criollismo independentista que condujeron la independencia perseguían dos grandes objetivos; por un lado, encarar los problemas heredados y, por otro, crear las estructuras de gobierno cuyo poder no pudiera ser por medios legales. ${ }^{12}$ Sin embargo, a la larga, ambos objetivos resultarían incompatibles porque esas estructuras eran una especie de seguro contra reformas necesarias, pero que se harían, con el tiempo, indeseables para os donos do poder político, religioso, social, cultural y económico en la región. ${ }^{13}$

Pero - y a pesar de su inestabilidad y del interminable de caudillos y de constituyentes - la política del siglo XIX latinoamericano no fue tan caótica como parece. Había reglas no escritas e instituciones de hecho que normaban la conducta pública. De tal modo que en la práctica, mientras existe un derecho ial, válido y vigente que de el orden social, paralelamente se genera un derecho no o ial válido, vigente y que opera de forma preminente en ese orden social. ${ }^{14}$ Precisamente, serán esas instituciones no

reconocimiento de la voluntad del pueblo, externada por escrito en el documento llamado Constitución. Es decir, el único titular de la soberanía es el pueblo (nación) que ejerce su poder cuando se constituye como Estado jurídicamente organizado, estableciendo la forma de gobierno, de los poderes públicos con sus respectivas facultades e identi an do las garantías individuales de los ciudadanos. Morlino, Leonardo, Como cambian los regímenes políticos, Madrid, Ediciones del Centro de Estudios Constitucionales, 1985; Bobbio, Nolberto et al., Diccionario de política, México, Siglo XXI Editores, 1983.

12 Zamorano Farías, Raúl, Entre la teoría..., cit.; id., Observando el orden social en México: el sistema de la política y el sistema derecho, México, Juan Pablos Editor, 2017.

13 La estructura del Estado se impuso y precedió a la formación de una sociedad nacional. Los Estados fueron impuestos por la colonización española y se implantaron en sociedades con características muy diversas y de compleja organización social. Sobre esto, y como referencia, véase el interesante trabajo de Faoro, Raymundo, Os donos do poder. Formação do patrónato político brasileiro, São Pablo, Editora Globo, 1998, así como el clásico trabajo de Arciniegas, Germán, Entre la libertad y el miedo, Santiago, Editorial del Pací o, 1954. Desde la literatura, Scorza, Manuel, Redoble por Rancas, Lima, PIESA-Edición Peruana, 1987; Fuentes, Carlos, La muerte de Artemio Cruz, México, Fondo de Cultura Económica, 1962; Asturias, Miguel Ángel, El señor presidente, Madrid, Cátedra, 1997, entre otros.

14 Teubner, Gunther, $O$ direito como sistema autopoiético, Lisboa, Edição da Fundação Calouste Gulbenkian, s/f., 1989. 
no escritas - el caudillismo, y no la ley-, las que garantizaron el orden basado en la lealtad personal para mantener unida a la sociedad.

Originario de aquella matriz, el sistema de la política y el constitucionalismo latinoamericano han estado cruzados por una historia intermitente de esfuerzos fallidos para superar el lastre del pasado, razón por la cual, la América hispana ha demostrado una insistencia casi laberíntica en las soluciones constitucionales a problemas políticos y económicos insolubles. Fórmulas constitucionales que se tornan más legibles cuando comprendemos su característica central, la cual ha sido, por lo general, que comúnmente ha servido para no cambiar nada y sólo perpetuar y/o reforzar el status $q u o,{ }^{15}$ estabilizando la primacía de las relaciones mecánicas o das (clientelares, de sumisión), cuyos conglomerados se subordinan a un superior (pater, caudillo, presidente), el cual lucha por sacar las mayores ventajas de esa sumisión.

Este particular tipo de estructuración del orden social reproduce además una ciudadanía que obedece generalmente por la antigüedad y tradición de la costumbre (uso), y en donde lógicamente la ley es siempre disponible — negociable por el más fuerte — en el sentido que está expuesta a ser supeditada a intereses considerados superiores (o al simple ejercicio de la materialidad de la fuerza física del poderoso. ${ }^{16}$

La proliferación y la estabilización de instituciones (políticas, jurídicas) orientadas por esta lógica han terminado por perpetuar los males que se proponía combatir, toda vez que éstas no sólo previnieron contra el autoritarismo sino que incluso han sido incapaces e para aplicar la ley, minando la cooperación y potenciando regímenes dictatoriales o clientelares al tiempo que sus cláusulas han vuelto incierta la conducta política, pues el quehacer político en muchos casos no depende de algún poder constitucional o institución garante, sino de las promesas personales de las élites o de los caudillos políticos y económicos, cuando no de los militares. ${ }^{17}$ Baste observar, por ejemplo, que históricamente toda propuesta política y jurídica resultó ser únicamente una iniciativa impuesta - incluso cuando no fueran

15 Loveman, Brian, The Constitution of Tyranny. Regimes of Exception in Spanish America, Pittsburgh, University of Pittsburgh Press, 1993, p. 62.

16 Zamorano Farías, Raúl, Observando el orden..., cit.

17 La sola idea de discutir o convocar al rediseño del contenedor constitucional ha terminado, en muchos casos, en golpes de Estado o en asonadas desestabilizadoras en un número signi ativo de países en la región. 
legales - por quien "como gobierno" ocupaba el Estado en un momento particular (presidente).

Precisamente esta práctica se ha naturalizado hoy en día y tiene una importancia extraordinaria toda vez que la del presidente y la institución presidencial han adquirido una cuantía inusitada y cuasi perniciosa. ${ }^{18}$ En tal sentido, en la actualidad y junto con el tema de la estabilidad política de los países en la fase de "postransición" y cambio político, uno de los ejes centrales que guía la discusión sobre la de los "regímenes políticos democráticos" obedece a las condiciones de gobernabilidad y de sus sistemas de gobierno. Discusión que gira en torno al problema de si las naciones de la región pudiesen estar mejor representadas por el parlamentarismo, el presidencialismo o alguna forma híbrida de sistema político. ${ }^{19}$

Ebergenyi y Sartori ${ }^{20}$ han señalado que el presidencialismo, como forma institucional en la cual recae la responsabilidad de dirigir los destinos de las naciones, es un concepto típicamente usamericano del poder político. Históricamente, la institución presidencial se creó en América ya que cuando los Estados europeos empiezan a practicar el gobierno constitucional, todos (a excepción de Francia que se convirtió en República en 1870) eran monarquías; y las monarquías ya tenían un jefe de Estado hereditario. Sólo hasta bien entrado el siglo XX Europa dio cabida a los presidentes electos (1919), mientras en América casi todos los países conquistaron su inde-

18 La institución presidencial deviene una potencia cuasi irrefrenable, piénsese en los casos de Venezuela, México, Chile o Brasil. A modo de síntesis y sobre la evolución de esta tendencia histórica, véase Linz, Juan y Valenzuela, Arturo (eds.), The Failure of Presidential Democracy: The Case of Latin America, Baltimore-Londres, The John Hopkins University Press, 1993; Linz, Juan J., La quiebra de las democracias, Madrid, Alianza, 1996; Mainwaring, Scott y Shugart, Mathew, Presidentialism and Democracy in Latin America, Cambridge, Cambridge University Press, 1997; Valenzuela, Arturo, Presidencialismo y parlamentarismo en América Latina, México, Instituto Federal Electoral, 1998; Diamond, Larry y Plattner, Marc F., (comps.), El resurgimiento global de la democracia, México, UNAM, Instituto de Investigaciones Sociales, 1996.

19 Llegando a confundir u homologar la expectativa democrática con la gobernabilidad. Quizás también en ello radica que gran parte del análisis sobre el constitucionalismo en América Latina continúa orientado por la escuela de la transición democrática vía élites (O’Donnell, Guillermo, "Delegative Democracy", Journal of Democracy, vol. 5, núm. 1, 1994; id., Contrapuntos, Barcelona, Paidós, 1997).

20 Chao Ebergenyi, Guillermo, "Orígenes del presidencialismo. Un concepto americano del poder político", Confluencias Núm. 3, México, vol. I, 1996; Sartori, Giovanni, Ingeniería constitucional comparada. Una investigación de estructuras, incentivos y resultados, México, Fondo de Cultura Económica, 1996. 
pendencia como Repúblicas (excepto, temporalmente, Brasil y, en cierto modo México a mediados del siglo XIX) y, por tanto, debieron elegir desde el primer momento a sus jefes de Estado, es decir, a sus presidentes. (La Constitución estadounidense de 1787 deja pocas dudas sobre qué era lo que importaba y cuál era el orden jerárquico al respecto.)

En esta perspectiva el presidencialismo ha sido entendido como un régimen en el cual el presidente es siempre el titular del Poder Ejecutivo, elegido mediante voto popular o, como ocurre en los Estados Unidos, a través de un Colegio Electoral sin mayor autonomía esencial con respecto a las preferencias populares y donde los periodos de gestión para el presidente y la asamblea son fijos. ${ }^{21}$

Como señala Sartori, ${ }^{22}$ existen dos criterios mínimos para definir a los sistemas presidenciales: por un lado, el criterio definitorio de un sistema presidencial es la elección popular directa o casi directa del jefe de Estado por un tiempo determinado, el cual puede variar de cuatro a ocho años. Sin duda este criterio es una condición definitoria necesaria, pero no suficiente. Por otro, en los sistemas presidenciales el gobierno, o el Ejecutivo, no son designados o desbancados mediante el voto parlamentario. Los gobiernos son una prerrogativa presidencial; es el presidente el que a su discreción nombra o sustituye a los miembros del gabinete. Los miembros del gabinete deben su designación al presidente y, aun en el caso de la censura parlamentaria, no se viola este criterio porque sigue siendo el presidente el que retiene, unilateralmente, el poder de nominación para llenar los puestos como mejor le parezca.

Lo anterior se vincula estrechamente con el ámbito de la eficacia en la toma de decisiones políticas. El gran problema de esta dinámica consiste en la primacía casi absoluta del presidente, lo cual genera y estabiliza un esquema en el que cada mandatario puede monopolizar los canales de agregación de intereses dejando de lado al resto de las instituciones. ${ }^{23}$ Juan

21 Mainwaring Scott y Shugart, Matthew, "Juan Linz: presidencialismo y democracia. Una revisión critica”, Desarrollo Económico. Revista de Ciencias Sociales, México, núm. 135, vol. 34, octubre-diciembre de 1994; Linz, Juan y Valenzuela, Arturo (eds.), The Failure of Presidential Democracy: The Case of Latin America, cit.; Linz, Juan J., La quiebra..., cit.; para una comparación con Europa, véase Carducci, Michele, "Parlamento: presidenzialismo e coalizioni elettorali", Quaderni Costituzionali, Italia, año XVIII, núm. 1, 1998.

22 Sartori, Giovanni, Ingeniería constitucional..., cit.

23 Situación que en la actualidad se ve doblemente reforzada cuando la lógica de la 
Linz observó que en los sistemas presidenciales el Ejecutivo, elegido directamente por el pueblo, por un término e independiente del voto de de los parlamentarios, tiene poderes constitucionales considerables que incluyen, generalmente, un control pleno sobre la composición del gabinete y la administración.

Pasquino refuerza esta idea cuando señala que la forma de gobierno presidencial se caracteriza, en su estado puro, por la concentración en un cargo único de los poderes de jefe de Estado y de jefe de gobierno. Es el presidente quien representa a la nación en las relaciones internacionales, quien estipula, aunque sujeto al consenso del Senado, los tratados internacionales; además de tener el poder y la competencia para declarar la guerra. Por último, es él quien tiene la iniciativa en las leyes más importantes, siendo por lo general fuente de decisiones. ${ }^{24}$ Así, no sólo es el poseedor del Poder Ejecutivo sino también el jefe simbólico del Estado y únicamente puede ser destituido entre elecciones por el drástico peso de la impugnación. ${ }^{25}$

No obstante, la evaluación del presidencialismo, lejos de ser esperanzadora, es más bien negativa pues, para Sartori, Linz, Pasquino y otros, el presidencialismo, por mucho, ha funcionado mal. La única excepción la constituye quizás Estados Unidos, pero todos los demás sistemas presidenciales han sucumbido regularmente a golpes de Estado y otras calamidades.

Acaso sea por ello que los estadounidenses, inventores del presidencialismo, se cuidaron (negaron) de entregar el poder a una sola persona. Allí el pueblo vota por sus legisladores y electores; los electores del pueblo eligen luego al presidente y todo el proceso es sancionado por el cuerpo legislativo. Con ello, la separación de poderes y atribuciones queda —al menos formalmente- establecida y articulada. El modelo está así caracterizado, más que por cualquier otra distinción, por la división de poderes entre el

representación deviene en autorrepresentación de una casta política que alberga todas las tendencias, colores y pedigree.

24 Pasquino, Gianfranco, voz "Formas de gobierno", en Bobbio, Matteucci y Pasquino, Diccionario de politica, México, Siglo XXI Editores, 1983.

25 El presidente es elegido por sufragio universal por el electorado, subdividido - $\mathrm{O}$ no- en colegios electorales. En dicha fórmula de gobierno, el presidente ocupa una posición central respecto de todas las fuerzas e instituciones políticas. Es absolutamente claro que un sistema presidencial puro no puede permitir ninguna clase de 'autoridad dual' que se interponga entre el presidente y su gabinete... La línea de autoridad debe estar claramente establecida desde el presidente hacia abajo. Linz, Juan J., La quiebra..., cit.; Diamond, Larry y Plattner, Marc F. (comps.), El resurgimiento global de la democracia, México, UNAM, Instituto de Investigaciones Sociales, 1996. 
presidente y el Congreso, lo que permite como un gobierno de instituciones separadas que comparten el poder, o como un gobierno de instituciones separadas que compiten por el poder compartido, de forma tal que la separación de poderes impide al Parlamento interferir en los asuntos internos que corresponde al campo del Ejecutivo; es decir, en ningún caso éste puede destituir al presidente.

Lo anterior lleva a suponer - básicamente- que los sistemas presidenciales conducen a un gobierno fuerte y efectivo, fundamentalmente en relación con la ágil vehiculación de las decisiones, evitando el asambleísmo; tendencia tan implícita en el parlamentarismo. Sin embargo, uno de los problemas que se detectan y que está relacionado con los partidos políticos (no sólo estadounidenses) es que su momento de mayor relieve, visibilidad y activismo, la única fase en la que cumplen una función en el nivel nacional, se da en el proceso de selección del candidato presidencial en la llamada nomination y en el folklore que caracteriza las llamadas conventions (que ha devenido en un verdadero y patético show político). ${ }^{26}$ En los hechos, el supuesto de agilidad queda operativamente cuestionado.

Además, puesto que el Congreso reacciona a las iniciativas presidenciales, aunque rara vez tiene capacidad o voluntad de asumir por sí mismo la iniciativa, se cae fácilmente en la parálisis institucional debido, obviamente, en gran parte a la decadencia de los partidos, causa y efecto de la fragmentación de la representación política y su falta de cohesión. ${ }^{27}$

Si los estadounidenses tienen una maquinaria constitucional diseñada para la parálisis gubernamental — como señala Sartori—, este defecto surge con todas sus fuerzas cuando se exporta su presidencialismo. Aunque en América Latina se encuentran la mayoría de los sistemas presidenciales, entre otras por las causas históricas indicadas, es también aquí donde estos sistemas un impresionante historial de fragilidad e inestabilidad. ${ }^{28}$

En la región, la institución presidencial ha derivado en un presidencialismo obsceno, abusivo y excesivo que genera una imagen omnipresente y omnia-

\footnotetext{
26 Pasquino, Gianfranco, voz "Formas de...", cit.

27 Sartori, Giovanni, Ingeniería constitucional..., cit.
}

28 El problema clave sigue siendo el mismo: fragilidad o ausencia de administración, para no mencionar un cenagal de corrupción. En la actualidad, la descarada nueva clase adinerada resulta que no es menos corrupta que las antiguas y arrogantes élites compradoras que solían dirigir nuestros países como feudos. Por ello es posible sostener que la corrupción no es una categoría analítica, sino un esquema, una realidad, un script cultural que operativamente se ha estabilizado en nuestra región. 
barcadora, así como una concentración absoluta del poder, precisamente en la de una persona. ${ }^{29}$ Operativamente, esta forma de organización del régimen político avala que los presidentes tengan un poder absoluto, pues en general poseen el poder para vetar secciones de leyes, gobernar por decretos y, a menudo, abusar de amplios poderes en situación de "emergencia". Empero, sin utilizar casi nunca este poder para forjar estructuras sociales o instituciones capaces de solucionar los problemas coyunturales y superar los momentos de tensión mediante legitimidad jurídica.

$\mathrm{Al}$ contrario, lo único que por lo general produce es mayor confusión, despertando la insaciable tendencia a medidas de fuerza y/o respuestas de carácter autoritario. Además, lo anterior, paradójicamente, abre las puertas para que mandatarios (o partidos políticos liderados por el caudillo) que en el pasado realizaron una pésima gestión, tengan la oportunidad de regresar a la Presidencia, toda vez que la creencia en el caudillo y en su carisma, dos elementos que en una democracia débil sin institucionalización pero fuertemente autoritaria, son capaces de imponerse sobre un pasado caracterizado por la ine iencia en la gestión y por encima de fundadas sospechas de corrupción (en la actualidad los casos de México y el retorno del PRI o el Chile de Bachelet, entre otros).

Precisamente, durante las últimas décadas observamos la permanente tensión en los sistemas presidenciales a raíz de la concentración excesiva de funciones y atribuciones en el presidente de la República, quien — cuando no lo controla o coopta - oblitera a un segundo plano la acción del Congreso nacional. ${ }^{30}$

29 El control del Poder Ejecutivo, tomado por presidentes que no lo eran en el sentido republicano de la palabra, sino émulos del absolutismo que acababan por desconocer la propia institución, generando serios problemas políticos y de orden institucional y social (Brasil, Venezuela). De esos excesos se derivan las diversas subespecies del presidencialismo criollo: el sátrapa, el caudillo, el patriarca, el cacique y el amo de estancia.

30 Sabido es que la concentración de funciones y atribución en demasía, de poder personalizado, ha generado fuertes crisis en las democracias del continente, también es sabido que en la actualidad la gran mayoría de las democracias estables en el mundo son regímenes parlamentarios, donde el Poder Ejecutivo es generado por mayorías legislativas y depende de éstas para su sobrevivencia. A diferencia del sistema presidencial, el sistema parlamentario se caracteriza, en un sentido estricto, porque la única institución democráticamente legítima es el Parlamento. En este régimen, la autoridad del gobierno depende completamente de la con nża parlamentaria; aquí los primeros ministros no pueden apelar directamente al pueblo pasando por encima de las cabezas de sus representantes. 
Si la modernidad de la sociedad moderna se caracteriza por la preminencia de la diferenciación funcional las operaciones, en donde los efectos de los diversos sistemas funcionales se combinan, se o se estorban y, por consiguiente, producen estructuras, modelos y formas de memoria cultural distinta, ${ }^{31}$ en el esquematismo del régimen presidencial estos presupuestos evolutivos incorporan principios contradictorios y devienen confusos pues, de una parte, estos sistemas empiezan por crear un Ejecutivo fuerte y estable, con legitimación plebiscitaría como para mantenerse contra la gama de intereses particulares representados en el Legislativo ${ }^{32} \mathrm{y}$, por otra, las Constituciones sin embargo, una profunda de la personalización del poder, tal que entre los frenos constitucionales, el principal es la prohibición de la reelección, al menos de forma inmediata. ${ }^{33}$

Aquí precisamente se encuentra una de las extravagancias y debilidades sustanciales del constitucionalismo presidencial; la contradicción fundamental entre el deseo de un Ejecutivo fuerte y estable y la latente en ese mismo poder presidencial, que viene a afectar la toma de decisiones, el estilo de liderazgo, las prácticas políticas y la retórica, tanto de los presidentes como de sus opositores. Así, mientras la representación política supone e imparte flexibilidad al proceso político, en la práctica el presidencialismo lo vuelve rígido.

Como se ha señalado, una primera consideración, al observar la operación de este esquematismo en la región, es el excesivo poder político concentrado en la presidencial y su fuerte vinculación con la implementación de programas políticos "monotemáticos". Programas que se articulan en torno a coyunturas muy , abandonando el trabajo político del proceso decisorio. En Chile, por ejemplo, la obsesión casi demencial del gobierno de la Concertación de Partidos por la Democracia (M. Bachelet) se concentra en mantener los así llamados indicadores macroeconómicos (obsesión por la economía). En Argentina, lógicamente, la preocupación macrista gira en torno a mantener la estabilidad alcanzada tras la crisis económica, sin que exista un acuerdo amplio entre los diversos sectores

\footnotetext{
31 Luhmann, Niklas, La sociedad..., cit.

32 En la concepción rousseauniana de la democracia implicada por la idea del pueblo, por quien se supone que habla el presidente, esos intereses carecen de legitimidad y el con cto de grupos de interés puede manifestarse en espacios no estrictamente políticos.

33 En la región ha existido un frívolo interés, vía decretos, fórmulas y reformas legalistas a la Constitución, para superar este "impase" (verbi gratia: Brasil, Chile, México, Venezuela).
} 
para buscar vías alternativas. En Colombia, el presidente Santos privilegia como foco de atención exclusiva a los acuerdos de paz con la guerrilla y al de drogas; en Perú, Kuczynski se concentra sobre los problemas heredados, asociados a la en la gestión pública, en Venezuela Maduro circula entre la constituyente, la nueva política económica y el chavismo popular y en México, a "pesar de Trump" y la corrupción institucionalizada, para Peña Nieto es lo bueno lo que cuenta. Evidentemente, esto restringe al máximo la gestión ejecutiva de la función presidencial y las posibilidades de consolidación democrática, pero a su vez va estabilizando precisamente estas lógicas. ${ }^{34}$

Podemos observar además que otro de los aspectos que tensiona a los sistemas presidenciales, es que tanto el presidente como las cámaras tienen razones para considerarse y proyectarse legítimos, pues ambos poderes han sido elegidos por voto popular, y su origen y sobrevivencia es mutuamente independiente. Así, en caso de intereses opuestos no hay ningún principio democrático que pueda resolver las disputas entre el Ejecutivo y la legislatura acerca de cuál de los dos representa realmente la "voluntad" del pueblo. ${ }^{35}$

Quizás, como han observado recientemente algunos teóricos y políticos, lo que se requiere en los sistemas de gobierno de la región sea reordenar el mapa de toma de decisiones políticas. ${ }^{36}$ Dicho en otras palabras, se requiere determinar con claridad los límites y las funciones del presidente y

34 Baste recordar los problemas y la aguda crisis política que debió enfrentar el gobierno de A. Fujimori en Perú, la caída de Mahuad en Ecuador, la crisis política de Argentina bajo el gobierno de Menen o de Macri en nuestros días, otrora el cuasi golpe de Estado contra Hugo Chávez y las diatribas escatológicas de Maduro en Venezuela, los constantes cuestionamientos a la acción presidencial en Colombia debido a la guerrilla y el narcotrá o, la destitución "constitucional" de Dilma Rousse en Brasil, la corruptela que han dejado instalada los diversos gobiernos de la Concertación de Partido por la Democracia en Chile y el actual patético clima político que dejó instalado en México el ex presidente Felipe Calderón.

35 Mainwaring, Scott y Shugart, Matthew, "Juan Linz...", cit.; Linz, Juan J., La quiebra de..., cit.

36 Lo cual no signi a instalar el tema de la "gobernanza" como sustituto funcional para promover la ciudadanía y democracia vía consensos y coordinación social. Reinstalar el problema técnico de la gobernabilidad es continuar con la funcionalización de los mecanismos de control social, toda vez que se recrea un imaginario del deber ser ("en la medida de lo posible"), en donde el control y la gestión ticiamente parecen compar tirse (gobierno-sociedad). Lo anterior constituye la característica central de las actuales democracias, como se indica y reitera en los informes del PNUD (2004). Con la gobernabilidad se restringe y concibe el proceso democrático como un método/procedimiento, 
sus respectivos ministerios y establecer, a la vez, una relación da con el Congreso como órgano representativo, manteniendo siempre el presupuesto jurídico de independencia y atribuciones de cada uno. Operativamente esto implicaría implementar dinámicas consensuales y de control (accountability), abordadas a partir de programas condicionales plausibles, con el

de establecer acuerdos capaces de impulsar un nuevo modo de acción política, al tiempo de hacer que las estructuras sociales estén disponibles y sean operativas, precisamente para desplegar en los hechos estos programas condicionales. ${ }^{37}$

Como sea, los dilemas que presentan nuestras sociedades no pueden ser entendidos solamente como el resultado de los problemas generados por la forma que asume el sistema político (presidencial, parlamentario o semipresidencial), o por la lógica tradición/modernidad. Por el contrario, resulta imperativo tener en cuenta las trabas, las exigencias y los desafíos de operatividad, regulación y coordinación entre los diferentes sistemas sociales, sus estructuras así como las expectativas cognitivas y su plausibilidad, que instala y presupone la modernidad de la sociedad moderna. Quizás, como señala Luhmann, simplemente por el hecho de que la sociedad global no se regula a sí misma mediante metas o normas o directivas cuya observancia regional pueda por lo tanto ser comprobada y eventualmente corregida, sino que los centros de la sociedad mundial... producen que regionalmente llevan luego a estructuras disipativas y a la permanente necesidad de autorganización. ${ }^{38}$

Hemos observado que en la región, uno de los rasgos más distintivos del modelo de modernización ha sido la forma sui generis de estabilización de las estructuras constitucionales-legales, cuando no su crónica fragilidad, en

sin determinar ni de irla con ctualidad y luchas por un posible consenso y menos aún la discusión por y en la toma de decisiones y por las formas de participación.

37 Paralela a las dimensiones técnicas e institucionales, se debe prestar atención a la forma en que se estructura la competencia politica en sistemas de elecciones presidenciales directas, los estilos de liderazgo, las relaciones entre el presidente, las élites políticas y la sociedad en general, las formas en que se ejerce el poder y se resuelven los con ctos, pues el presidencialismo se torna problemático al operar según la norma de que el ganador se lo lleva todo, haciendo de la política representativa un juego de suma cero, lo que agrava la rigidez del sistema, ya que vencedores y perdedores están claramente de idos por todo periodo del mandato presidencial, haciendo inviable cualquier posibilidad de alianzas o cooperación. Este juego suma cero aumenta los intereses y exacerba las tensiones y cortocircuitos del sistema. Linz, Juan J., La quiebra de..., cit.

38 Luhmann, Niklas, La sociedad de..., cit., p. 640. 
donde uno de los problemas fundamentales ha sido el desarrollo de un solo nivel simbólico. Por ejemplo, las lógicas evolutivas de la modernización y el desarrollismo potenciaron sólo una variable o constelación de garantías: la política o, en el último tiempo, la economía, suprimiendo cualquier dimensión de ciudadanía y promoviendo, generalmente, una lógica de desdiferenciación operativa y consecuente corrupción de los códigos políticos, económicos y sociales, aun cuando las concepciones doctrinales sobre la necesidad del "desarrollo económico", como soporte del desarrollo social, hayan sido puestas tanto desde el lado de los "revolucionarios" de izquierda, cuanto de los "conservadores" de derecha.

Ciertamente, esta propensión a la debilidad institucional y de carencia estructural operativa (estancamiento y centralismo político), poco ha ayudado en el proceso de diferenciación funcional ya que, por lo general, éste ha derivado en mecanismos abusivos y de excepción donde lo que ha primado han sido los pactos como vínculos reales entre actores reales; caudillos, familias poderosas, cuerpos militares, grupos corporativos, empresarios, la iglesia y, en la actualidad, la absoluta preminencia de las castas, como expresión operativa que articula la lógica de la política, lo cual termina por socavar las bases de la representación e instala los cimientos de la "democracia" delegativa. ${ }^{39}$

En este escenario, las antiguas diferencias entre izquierda y derecha se han disuelto ante este suelo común, constituido por una racionalidad puramente tecnoeconómica y mediática, donde la única expectativa que orienta el orden social está puesta en la "sana competencia" por la "competitividad" y el globalismo económico, como alternativa, a un proceso de mundialización que todavía no somos capaces de aprehender. ${ }^{40}$

\footnotetext{
39 Para O’Donnell las democracias delegativas simulan tener las características de una democracia liberal pero con instituciones políticas débiles que son aprovechadas por los políticos que ejercen el poder con grante violación de los derechos fundamentales. Tampoco se trata de abogar por sistemas de gobierno parlamentario para la región, sobre todo cuando el esquema cultural político de nuestros países imposibilita la existencia de este tipo de regímenes, pues si la cohabitación representa un serio problema para Francia (Sartori, Giovanni, Ingeniería constitucional..., cit.), ese fenómeno en América Latina podría traer como resultado pésimas consecuencias para la ya frágil estabilización de los sistemas, principalmente del sistema de la política y del derecho. O'Donnell, Guillermo, "Delegative Democracy", Journal of Democracy, vol. 5, núm. 1, 1994, pp. 55-69.

40 Independiente de este hecho, no podemos dejar de considerar que la complejidad funciona bien donde alcanza una velocidad de función y donde se equilibran y contrapesan los diferentes (sub)sistemas, por ello una sociedad de orden diferenciado requiere de
} 


\section{El caso chileno}

En toda república hay dos espiritus contrapuestos: el de los grandes y el del pueblo, y todas las leyes que se hacen en pro de la libertad nacen de la desunión entre ambos.

Maquiavel $0^{41}$

En este contexto, ¿cuáles son los puntos críticos del sistema de gobierno, del presidencialismo y de las formas estructurales de la sociedad chilena y qué tipo de esquemas se han institucionalizado para organizar la inclusión operativa en la vida política y en los procesos de toma de decisiones, posterior a la dictadura militar?

Chile se articula y orienta constitucionalmente por una forma de gobierno presidencial, ${ }^{42}$ con un sistema bipartidista (en el cual no se prevé esta situación así como tampoco posibilidad alguna de convocar al poder constituyente para redactar una nueva Constitución $)^{43}$ y un comportamiento

una mayor individualidad de las expectativas, pero no en el sentido del individualismo mercantil sino institucional. Una suerte de institución que garantiza la civilización de las expectativas. Luhmann, Niklas, La sociedad de..., cit.

41 Maquiavelo, Nicolás, Discursos sobre la primera década de Tilo Livio, Madrid, Alianza, 2009, p. 42.

42 Artículo 32o. (Diario Oficial de la Federación, núm. 8, 24 de septiembre de 1980, CPR). Las atribuciones del presidente de la Republica son: "Ejercer la potestad reglamentaria en todas aquellas materias que no sean propias del dominio legal, sin perjuicio de la facultad de dictar los demás reglamentos, decretos e instrucciones que crea convenientes para la ejecución de las leyes".

43 Una de las grandes promesas de la actual presidenta chilena Michelle Bachelet durante su campaña para optar por segunda vez a la Presidencia en las elecciones de 2013, fue la creación de una nueva Constitución y no sólo reformarla. Si bien la Constitución de Pinochet ha tenido algunas modi aciones en estos 26 años, hasta ahora esas reformas sólo se circunscriben a la forma mas no al contenido. Recordemos que la reforma de 1989 decreta el mínimo espacio constitucional imprescindible, pero sin la activación de un poder constituyente democrático: leyes de amarre (CPC, 1980). La reforma de 2005 tuvo por objeto democratizar plenamente la norma fundamental, eliminando esos "enclaves autoritarios" de la Constitución, sólo que la característica de itoria de esta reforma es que resulta imposible de salvaguardar a través del poder de reforma (Ley núm. 20.0502, contenida en el Decreto Supremo núm. 100, publicada en el Diario Oficial de la Federación del 26 de agosto de 2005). Por ejemplo, en los hechos se mantiene la representación política no proporcional, asegurando a la derecha un puesto clave de "representación", en tanto "segunda mayoría". 
electoral cuyo pivote na un enfoque individualista (racional choice), lo cual determina el carácter del sistema político junto con las expectativas de las personas en relación con el sistema político y la "democracia". ${ }^{4}$

Un sistema político, diseñado en la postrimería de la dictadura, que limita constitucionalmente la participación a dos bloques políticos para su alternancia en el manejo del poder y el uso del gobierno. Y si bien existen diferencias de forma - pero no de contenido - entre ambos bloques para hacer sostenible la operatividad del sistema, se fomenta el dominio total de los aparatos de los partidos, con listas de participación política y social siempre cerradas y con una participación (democracia) interna inexistente. ${ }^{45}$

Amparados en el contenedor constitucional heredado de la dictadura militar, las coaliciones de partidos políticos (Concertación Democrática y Alianza por Chile) han eliminado la organización social mientras can la política en aras de una racionalidad estratégica (normatividad del deber ser "en la medida de lo posible", para terminar en la medida de lo conveniente). ${ }^{46} \mathrm{~T}$ axiomática que hace casi imposible nuevas alternativas y posibilidades de poder distintas de la misma.

Este giro tecnoburocrático (presente ya desde los albores de la llamada transición democrática) se ha impuesto a la subjetividad y al esquema cul-

44 Chile gozó en el pasado de una fuerte institucionalidad de su sistema de partidos (columna vertebral del sistema político), mas en la actualidad la con nza en estas instituciones ha mermado considerablemente. A lo anterior se suman las di ultades pen dientes, heredadas de la dictadura, y las reiteradas denuncias de corrupción que afectan a miembros de los diferentes partidos políticos. Un sólo indicador: la no inscripción en los registros electorales de un signi ativo porcentaje de jóvenes (más de un millón en edad de ejercer este derecho ciudadano), sea por apatía y desesperanza aprendida, desciudadanización o de razón cínica. Es claro también que lo anterior abre las puertas a tendencias personalistas, impulsadas por el líder independiente, situado ahora sobre los desacreditados partidos políticos para ir "más allá" del corrupto sistema (¿qué tan más allá?) y "salvar" de nuevo al pueblo.

45 Entre las últimas "novedades" políticas sobresale el de las cúpulas dirigentes del Frente Amplio (2017), marcada por la polémica designación de candidato en donde, al parecer, el proyecto político de este conglomerado "para cambiar Chile" se reduce a ocupar un cargo político. Recordemos que incluso en las instalaciones de la dirigencia administrativa de la Central Única de Trabajadores (CUT), se impide u obstaculiza que los trabajadores que allí desempeñan sus actividades puedan sindicalizarse.

46 En la medida de lo posible, es el sacrosanto axioma que instaló el primer presidente democrático luego del pacto con la dictadura militar, Patricio Aylwin (1990-1994), cómplice del golpe de Estado de 1973 como queda en evidencia tras la desclasi ación de los documentos de la CIA (Informe Hinchey, Las actividades de la CIA en Chile, Washington, 2000.). 
tural de los individuos, ${ }^{47}$ determinando la forma en que éste se relaciona con la política. En la práctica, ha sido la operativización de la forma en la cual las condiciones económicas orientan y el comportamiento electoral y las preferencias de los individuos como condición de participación e inclusión social, las que se han estabilizado (soy ciudadano si ejerzo el voto y basta).

Al respecto, lo que ha cambiado no es sólo la perspectiva, sino también una práctica generada por el tránsito del voto ideológico al voto de carácter económico como impronta de inclusión social y, consecuentemente, de "ciudadanía". Un cambio donde lo que se busca es más bien determinar las preferencias electorales y estabilizar técnicamente la acción política como presupuesto democrático ("gobernabilidad"), un único esquema cultural (memoria) cuyo soporte es el script normativo heredado de la dictadura. ${ }^{48}$

Pero entonces, ¿de qué forma y en qué medida los presupuestos de primacía funcional se relacionan con los esquemas dominantes? ¿Cómo se acoplan las expectativas con un sistema político que en la práctica obstruye las formas de diferenciación y prescinde de los presupuestos y adquisiciones evolutivas en la modernidad de la sociedad moderna?

Es importante no olvidar que en Chile, la llamada transición democrática fue un cambio del autoritarismo militar al neoautoritarismo civil en un escenario en el cual ha predominado (desde 1990) un discurso que articula Estado, política y sociedad como clivaje, y donde se reconoce que lo político tiene su base en la sociedad. Mas, en la práctica, el accionar que opera es la preminencia de la lógica entre "orden" y mercado. En este sentido resulta sintomático cómo algunos grupos políticos, vinculados fuertemente a los sectores económicos criollos o foráneos, sostienen que cualquier idea de democracia y de coordinación social puede ser reducida a la potencialidad de los mercados, llegando al extremo de medir la democracia y el derecho con la vara de las ganancias y la utilidad, lo cual deviene en la de los individuos y la supresión de la política. ${ }^{49}$

\footnotetext{
47 Moulian, Tomás, Chile actual, anatomía de un mito, Santiago, Editorial LOM, $1997 b$.

48 La más clara señal de la naturaleza abortada de las transiciones políticas y los regímenes electorales civiles está de ida por: impunidad al ejército, continuidad de la legislación represiva y políticas socioeconómicas regresivas.

49 Castoriadis, Cornelius, Le monde morcelè. Les carrefours du Labyrinthe, Francia, Editions du Seuil, 1990.
} 
Sumado a lo anterior, los regímenes civiles que han gobernado al país durante 27 años (de centro, izquierda y derecha, sea lo que se quiera entender hoy con estas denotaciones), han promovido y privilegiado estructuras que fomentan el culto personal, el rito electoral, así como la pugna entre los partidos y el mantenimiento de ciertas libertades individuales (consumo), todo ello al interior de los parámetros establecidos por su pacto con el ejército (la llamada transición democrática).

En ese contexto, un sistema político presidencial y de representación bipartidista cuyo contenedor constitucional fue diseñado por la dictadura militar, los que gobiernan buscan mantenerse en el poder, la oposición busca hacerse con el poder (por el poder) y los electores votar por el partido que les brinde (discursivamente) más

y maximice sus expectativas primarias (consumo). Precisamente, todo ello permite - a los expertosseñalar que en Chile las instituciones "democráticas" funcionan. ${ }^{50}$

En tal sentido, y con el cinismo característico de la nueva casta política que ha gobernado a Chile en las últimas dos décadas (y que cada día se asemeja más al esquema político-cultural mexicano), tiempo atrás el ex presidente de la República Ricardo Lagos (2000-2006) manifestó reiteradamente su orgullo por el hecho de que "las instituciones funcionan en Chile". Lo que Lagos no dijo fue que las instituciones - cuyo funcionamiento alabó- son las instituciones impuestas al país por la dictadura, las cuales van desde la educación municipalizada hasta el sistema fuertemente presidencial, pasando por un Congreso elegido sin representación proporcional (que hasta hace poco tiempo tuvo senadores designados y vitalicios), la inamovilidad de los jefes de las fuerzas armadas y un consejo de seguridad nacional con fuerte presencia de los poderes fácticos. ${ }^{51}$

50 Chile se ha convertido en un país ejemplar para invertir y hacer negocios. La oferta en el mercado de artículos da cuenta de un acelerado crecimiento económico en los últimos 25 años. A la par, con el "progreso" la brecha de ingresos y oportunidades entre los más ricos y los más pobres aparece también como una de las causas del aumento de la violencia y de la delincuencia en el país (PNUD, 2004-2015).

51 La Constitución de 1980 de e las normas para la vigencia de un sistema políti co binominal, leyes orgánicas constitucionales que legitiman los enclaves autoritarios, imposibilidad de reformar la Constitución debido a la lógica de representación política que se produce entre mayoría y minoría con uradas en dos bloques y la operatividad de poderes fácticos a través del lobbing (utilización de la in encia política para los negocios o para el enriquecimiento ilícito, o indirecto; in encia de grupos empresariales en las deci siones públicas). Zamorano Farías, Raúl, "Logiche di...", cit. 
Con la posibilidad que brinda la mirada retrospectiva, es importante observar que el ethos democrático chileno, durante el siglo XX hasta 1973, estuvo siempre orientado por una visión integrativa de la sociedad, cuyo objetivo era superar las exclusiones y ampliar, a través de la institucionalización y universalización normativa, los derechos políticos y sociales. Ello bajo la égida de un sistema político fuertemente central que mediaba y articulaba los modos

tensos y cambiantes en las relaciones de las distintas fuerzas sociales en disputa por el campo sociocultural y político. Condiciones en las cuales el proceso de autoproducción de sociedad debía negociarse políticamente (en el marco normativo constitucional) con el conjunto de las otras fuerzas sociales, característica del compromiso interclases. ${ }^{52}$

Desde los años treinta (tras la bancarrota de la oligarquía) y hasta el 11 de septiembre de 1973, la construcción del orden social en Chile desarrolló y articuló una relación de tres procesos paralelos: a) un creciente proceso de democratización e inclusión político-normativa que abarcó un espectro partidario completo, de derecha a izquierda; $b$ ) una progresiva participación ciudadana que se consolida en la década de los sesenta y que una fuerte presión de las capas medias y de los sectores populares organizados, y c) un proceso de industrialización por sustitución, aunque incompleto, en el cual el cobre y su explotación siguen siendo la principal riqueza del país. Evidentemente, en este proceso el Estado tuvo un papel central y 53

Precisamente, la fuerza y el peso histórico de la institucionalidad, como fórmula de resolución de los y tensiones al interior del sistema de clases, es el factor que posibilita que el Chile de los años setenta haya sido descrito como uno de los países más "estables" del continente, gozando de una reconocida solidez institucional y tradición democrática. Una sociedad altamente clasista y diferenciada, pero con canales de participación pro-

52 El gobierno de Eduardo Frei Moltalva (1964-1970) tuvo como eje de su política la revolución en libertad, lo cual implicaba la necesidad de hacer cambios signi ativos en la estructura social del país (reforma agraria), pero respetando la Constitución del Estado. (Durante el gobierno de Salvados Allende, y como lo demuestran los documentos y registros históricos, el Partido Comunista compartía la misma lógica política; así, en los meses previos al golpe de Estado su orientación política abogaba por consolidar lo alcanzado y no avanzar sin transar, como predicaban los socialistas y su incendiario dirigente Carlos Altamirano. Importante señalar que en la actualidad tanto comunistas como socialistas tranzan todo cuanto pueden, mientras que del avanzar no se habla).

53 Moulian, Tomás, Democracia y socialismo en Chile, Santiago, FLACSO, 1983; Zamorano Farías, Raúl, Entre la teoría..., cit. 
fundamente institucionalizados, donde las principales vías para la acción y demanda social eran las organizaciones obreras (sindicatos), profesionales (gremios), estudiantiles (federaciones), sociales (juntas de vecinos) y, por supuesto, los partidos políticos, legitimados e institucionalizados como formas de acción histórica de la sociedad chilena. ${ }^{54}$

Tomás Moulian ${ }^{55}$ señala que luego de la salida de Pinochet, tras el amparo del predominio del orden, la y la efectividad de la gobernabilidad y el crecimiento económico (orientación exportadora y desregulación de la economía), las estructuras de clases y las organizaciones sociales fueron obliteradas y desconocidas, mientras se iban instituciones que "funcionaban" a la medida del nuevo patrimonialismo político. ${ }^{56}$ Patrimonialismo estamental de las élites políticas — cristalizado en la del presidente- que desde siempre rechazaron cualquier intento de renovación o transformación de las estructuras políticas e instituciones heredades de la dictadura. ${ }^{57}$

La operatividad jurídico-política de esta estructura, mantenida por los gobiernos y presidentes de turno desde 1990 a la fecha, tiene por resultado que en la actualidad se observe una tendencia a la fragmentación y desciudadanización de la ciudadanía y a la criminalización de las organizaciones

54 Allende, Salvador, Cinco discursos fundamentales. Allende, Santiago de Chile, Editorial Aun Creemos en los Sueños, 2008 (intervención ante la Asamblea General de Naciones Unidas, 4 de diciembre de 1972).

55 Moulian, Tomás, "El Chile actual y su secreto", Chile '96 Análisis y opiniones, Santiago, FLACSO, 1997; id., Chile actual..., cit.

56 La llamada transición política en Chile estuvo controlada por los partidos de la Concertación Democrática, los cuales aun cuando prometieron cambiar la Constitución de 1980, así como el modelo económico, en la práctica han operado al margen de la inmensa mayoría estabilizando tanto el modelo socioeconómico y político, cuanto la Constitución. Jocelyn-Holt, Alfredo, "Todavía vivimos bajo una dictadura", El Mostrador, Santiago, 29 de marzo de 2001; Zamorano Farías, Raúl, Entre la teoría..., cit.

57 No olvidemos que el de la dictadura en Chile estuvo condicionado a concesiones a la institucionalidad impuesta, lo cual está de ido en la Constitución de 1980. Lo anterior estaba claramente establecido ya en 1977 cuando, con ocasión del día de la juventud el 9 de julio (Discurso de Chacarillas), Augusto Pinochet explicitó muy claramente la estructura de la Constitución: reconocimiento de un gobierno cívico-militar, en donde los garantes de la institucionalidad y del orden serían los militares. Precisamente, el discurso de Chacarillas no habla de "transición" sino de consolidación. Jocelyn-Holt, Alfredo, idem. Sobre la base de ese ordenamiento cualquier reclamo o demanda social fue y es presentada como delincuencia y las protestas como atentados a la gobernabilidad y al orden público (como lo demuestra la prohibición para manifestarse frente a La Moneda -Palacio de Gobierno-, las sanciones a las comunidades mapuches, a las organizaciones estudiantiles y la reactivación de la Ley de Seguridad Interior del Estado). 
sociales. ${ }^{58}$ Todo ello orientado por ese contenedor constitucional, con su propia legalidad construida según conveniencias de la razón de poder, con la estabilización de grupos (económicos) que se aferran a sus privilegios y que hacen valer su propia institucionalidad, poco o nada democrática, pero que sí funcionan. "Funcionan" pero sólo para esta inmensa minoría. ${ }^{59}$

Lo anterior permite constatar el consecuente y profundo debilitamiento del sistema político y el cierre del acceso a otros actores en la disputa institucional, precisamente del poder político, reduciendo la identidad y los derechos ciudadanos a una dimensión única (civil en la gramática de Marshall) y la representación del en una retórica de oposición entre un ellos y un "nosotros" (cuya cabeza es la que autorrepresenta su propia casta política, sumando toda la lógica de un presidencialismo obsceno, abusivo y excesivo). ${ }^{60}$

Las consecuencias para un sistema político-democrático, que se dice representativo, son obvias: la ura presidencial no institucionalizada, sino determinada por la coyuntura, el dinero y los sobrentendidos políticos, junto a la capacidad de hacer sentir al ciudadano — por breves minutos - que forma parte del juego de la democracia (elección), pero sin ningún otro espacio de participación efectiva. Un sistema de partidos políticos devenido en casta y sustentado en presuntas dinámicas de competencia, que en el fondo se orientan a un perenne empate técnico entre el presidente y las cámaras. Donde además ninguno logra materializar sus propuestas, pero ambos mantienen a conveniencia el status quo.

58 Movilizaciones mineras en contra del Fondenor (Fondo de Desarrollo para el Norte) así como las grandes movilizaciones en Aysén, o las protestas en contra de la planta de Agrosuper (holding de empresas alimentarias chilenas) y por cierto, "las contundentes manifestaciones de los estudiantes secundarios en contra de la mercantilización de la educación”. Gutiérrez Martínez, Elia, El movimiento estudiantil secundario en Chile. Continuidades y cambios, México, UNAM, Facultad de Filosofía y Letras, tesis doctoral en pedagogía, 2017.

59 La idea liberal-burguesa de que los agentes individuales son los elementos constituyentes y los actores políticos efectivos de un régimen democrático, y la convicción puritana de que el fundamento de la vida democrática reside en la autonomía del individuo, entendida en términos de la soberanía, la racionalidad y la persona moral, en la actualidad parece agotar su capacidad explicativa. Véase Pereyra, Carlos, Sobre la democracia en México, México, Cal y Arena, 1990, p. 80; Baño, Rodrigo, "La transformación económico-social de Chile contemporáneo”, Revista Proposiciones, núm. 24, Santiago, Sur Ediciones, 1994.

60 El presupuesto operativo de la ciudadanía supone un respeto a la ley, ciertamente por la amenaza de represión, pero también se obedece porque se confía en la creación de normas racionales y, por tanto, universales y legitimadoras de la autoridad impersonal. 
En parte, ésta es otra de las estrategias que se implementan para que la política se mantenga como un asunto exclusivo de los profesionales, de los expertos en la técnica política. ${ }^{61}$

Tal perversión entre las palabras y las cosas ha dado por resultado que en la actualidad se genere la paradoja que en Chile se viva un proceso político que promueve ampliar la inclusión (participación), conjuntamente con la aplicación de un modelo institucional cuya lógica es el crecimiento económico y una brutal exclusión de importantes franjas sociales. Así, se ha ido consolidando un modelo que estabiliza la exclusión y la pobreza, y cuyo discurso se fundamenta en la famosa, y hoy fetichista democracia ritual. ${ }^{62}$

En la lógica operativa, tanto política como social, parece haberse objetivado casi de forma fetichista el "consenso" sobre un "compromiso de gobernabilidad" entre empresarios, clase política y militares, cuya razón tiene que ver con la mantención de las instituciones heredadas de la dictadura, con un esclarecimiento limitado y restringido en materia de derechos humanos y en donde cualquier cuestionamiento o "violación de estas reglas" es visto por el presidente en turno como un atentado contra $s u$ democracia. ${ }^{63}$

61 Desde la bancarrota de la oligarquía (1930-1940), la clase política en América Latina ha sido monopolizada por una burguesía dependiente (considerando la di ultad para de ir este conglomerado social, que no es ni unívoco ni heterogéneo); sobre cuya base se ha restructurado la actual clase política (expertos y tecnoburócratas que manejan las estructuras del Estado). En este escenario, un mínimo sector viene reclutado por adscripción ideológica mientras la clase política deviene una casta privilegiada.

62 Fetichización ideológica como sustituto de la realidad, lo cual es propio de la lógica moderna. Francis Bacon se refería (Novun Organum, 1620) al sustituto de las imágenes de ídolos como creaciones humanas. Hablamos, en cualquier caso, de sustitutos funcionales operativos, no de fetiches para remplazar la realidad como diría Marx, quien introdujo el concepto de fetichismo al analizar la verdad que oculta toda mercancía, vale decir, al estudiar el valor asignado el cual no equivale al valor real. Freud también se re re al fetichismo que lleva a algunos a concentrar el potencial libidinoso en objetos accesorios que operan como sustitutos del objeto real, como amar una prenda de vestir y no a su portador. Podría a marse que toda ideología ofrece objetos de sustitución (li bidinosos o no). Amar a un imaginario pueblo, a una clase social, a una bandera, a una cruz gamada, a una hoz y un martillo, al dinero y la e iencia o a un tipo de orden son sublimaciones y fetichizaciones al mismo tiempo.

63 Hablar de gobernabilidad es hablar de poder y de las formas y estrategias que adopta ese poder. La gobernabilidad es un hecho técnico no político (la mayor gobernabilidad, como equilibrio y control, está dada por el Chile de Pinochet o por la Alemania del Führer), ya que gobernabilidad es el uso de criterios y estrategias decisionales para operativizar un sentido. ¿Pero, cuál es el sentido, cómo se ha construido, sobre qué materialidad, sobre qué presupuestos, expectativas y experiencias? Esto es precisamente lo 
Quizás sea por ello que en el Chile actual, aun cuando se viva en el ritual de la democracia nadie cree en ella. ${ }^{64}$ El país más bien asemeja una jaula de hierro cercada por la rabia y el miedo neurótico, la apatía, la subliminal imposición del olvido, el consumismo y la corrupción. Con un sistema político económico que ha logrado mantener un crecimiento económico acelerado y sostenido pero también una de las peores redistribuciones del ingreso del mundo. Un sistema en donde conviven la las relaciones laborales, la precarización del trabajo y la baja capacidad generadora de empleo productivo con la paz social, un número controlado de huelgas y una baja tasa de sindicalización. Con una pobreza cada vez más difícil de combatir, con un crecimiento constante del consumo de las personas, apoyado por dispositivos crediticios; donde gracias a la ciudadanía cart, incluso los sectores más pobres pueden participar en el círculo eterno del consumo. ${ }^{65}$ Todo esto por la apatía y una desesperanza aprendida que va en aumento respecto de las expectativas, presupuestos y adquisiciones que orientan la ciudadanía, la política y hasta la democracia. ${ }^{66}$

En los hechos, tal concepción democrática de orden social remite más bien a la construcción de un esquema político mínimo, ${ }^{67}$ manejado e impuesto por raquíticos consensos de minorías y concertaciones cupulares y vigilado por la nueva casta política que custodia la norma heredada de los

que se oculta cuando se habla de la gobernabilidad, de la crisis del crecimiento o de la e acia.

64 Toda vez que el librecambismo se transforma la más de las veces en la radical negación de la democracia. En este sentido Bobbio insiste en la idea que la efectivización de una mayor protección de los derechos del hombre esta ligada al desarrollo global de la civilización humana. Por ejemplo, no se puede poner el problema de los derechos del hombre abstrayéndose de los dos grandes problemas de nuestro tiempo, que son los problemas de la guerra y de la miseria, del absurdo contraste entre el exceso de potencia que creó las condiciones para una guerra exterminadora y el exceso de impotencia que condena a grandes masas humanas al hambre. Bobbio Norberto, A era dos dereitos, Río de Janeiro, Editora Campus, 1992, p. 45.

65 Moulian, Tomás, Chile actual ..., cit.

66 Zamorano Farías, Raúl, Observando el..., cit.

67 Orientado por la lógica económica. Lo ejempli an las cifras: los quintiles uno y dos, los más pobres, consumen a través de créditos hasta nueve veces más que sus ingresos, por eso no se sienten pobres. En Chile el sistema mercantil es el soporte del modelo, porque a través del crédito se in la demanda, y para El Mercurio, la demanda es el motor de crecimiento del país. Sobre esto véase los sistemáticos y "sesudos" análisis económicos del periódico El Mercurio (2011, 2012, 2013, 2014, 2015). 
militares mientras difumina o culpabiliza cualquier movilización o irritación del ciudadano, porque para ellos éste no conoce, no conduce ni es capaz de decidir ningún problema. ${ }^{68}$ Así, estos sistemas de gobierno pueden seguir potenciando los rasgos patrimoniales presentes en los esquemas culturales de la política (autoritarismo, caudillismo, personalismo) y las $\square$ patologías propias de un orden del autoritarismo orientado y avalado por la

de la tradición centralista y del "señor presidente/a".

\section{Epít ome}

Si las expectativas se han institucionalizado de diversa manera dando cuerpo a diferentes formas y órdenes político-constitucionales (democracias consolidadas), los acomodos necesarios entre experiencia y expectativa para hacer que el sistema político funcione, son locales; asimismo, las leyes y la relación que un subsistema particular guarda con el todo están determinadas por la función específica del mismo. En tal sentido, los sistemas políticos, sean presidenciales o parlamentarios, pueden operar posibilitando la disponibilidad de estructuras y programas condicionales para asegurar la ejecución y toma de decisiones político-jurídicas, abriendo y generando siempre otras posibilidades que van ciudadanizando la ciudadanía al constitucionalizar la Constitución (pero no en lógica legalista de producir leyes y normas como sustituto funcional a la inoperancia de la ley), en tanto marco contenedor que orienta y genera confianza social. Lo cual constituye precisamente uno de los presupuestos de la democracia moderna.

Reproducir tal presupuesto y asegurar la estabilidad del sistema político (y la forma de gobierno) a través de un diseño institucional y constitucional operativo, que reconozca y tematice los presupuestos y ventajas evolutivas

\footnotetext{
68 En Chile se han instalado mecanismos que obedecen a la lógica de la "guerra preventiva", que divide al mundo en enemigos y amigos. Son "enemigos" los jóvenes que expresan su descontento por la ausencia de perspectivas de futuro, los estudiantes que se oponen a la mercantilización de la educación, los trabajadores sindicalizados que luchan por condiciones laborales dignas y los mapuches que exigen la restitución de sus tierras ancestrales. En esta lógica, se promueve e instala la confusión, donde todo es igual y por lo tanto todo da lo mismo, de modo que la política reinante paraliza y neutraliza. Zolo, Danilo, Il principato democratico. Per una teoria realistica della democracia, Milán, Feltrinelli Editore, 1992, p. 102; Sloterdijk, Peter, Crítica de la razón cínica, Madrid, Siruela, 2007.
} 
de la diferenciación funcional de la modernidad de la sociedad moderna, permite al sistema reaccionar ante nuevos parámetros, nuevas oportunidades y nuevas restricciones que están siempre en la lógica del mismo sistema. Es decir, hace plausible construir y generar posibilidades para crear un mapa de oportunidades y restricciones, estableciendo la manera congruente en la cual puede organizarse el poder político y ejercitarse jurídicamente a través de específicas delimitaciones legales; también que el sistema político pueda reaccionar ante aquellos cambios.

En caso contrario, las limitaciones y consecuencias que genera estabilizar sólo el aspecto económico (ganancias) o técnico (= gobernanza), o la permanente disponibilidad de la ley (que se ampara en la inmunidad/ impunidad del cargo o en atávicas prácticas y esquemas clientelares patrimoniales: órdenes estratificados), clausura las posibilidades de mantener un elevado nivel de alternativas decisionales no sólo en el ámbito político; sino también en el jurídico, el educativo, el científico y hasta en el religioso (un solo dios, una sola fe).

La plausibilidad de generar posibilidades y redimensionar el sistema de la política (y la operatividad del derecho), no significa pérdida de su importancia, sino restructuración reflexiv $a^{69}$ de su función básica en la articulación de los procesos operativos en una sociedad funcionalmente diferenciada; insisto, sea en un régimen presidencial o en un régimen parlamentario.

Posibilidades que — ciertamente - siempre se deben construir...

\section{BIBLIOGRAFÍA}

Allende, Salvador, Cinco discursos fundamentales. Allende, Santiago de Chile, Editorial Aun Creemos en los Sueños, 2008.

ARCINIEGAS, Germán, Entre la libertad y el miedo, Santiago, Editorial del Pacífico, 1954.

Asturias, Miguel Ángel, El señor presidente, Madrid, Cátedra, 1997.

BAÑo, Rodrigo, "La transformación económico-social de Chile contemporáneo”, Revista Proposiciones, Santiago, núm. 24, Sur Ediciones, 1994.

69 Teubner, Gunther, "Elementos materiales y reflexivos en el derecho moderno", en Bourdieu, Pierre y Teubner, Gunther, La fuerza del derecho, Colombia, Siglo del Hombre Editores, 2002. 
Bobbio, Norberto, A era dos dereitos, Río de Janeiro, Editora Campus, 1992.

Bobbio, Norberto, Matteucci , Nicola y Pasquino, Gianfranco, Diccionario de política, México, Siglo XXI Editores, 1983.

Carducci , Michele, "Parlamento: presidenzialismo e coalizioni elettorali”, Quaderni Costituzionali, Italia, año XVIII, núm. 1, 1998.

Cast oriadis , Cornelius, Le monde morcelè. Les carrefours du labyrinthe, Francia, Editions du Seuil, 1990.

Chao Ebergenyi, Guillermo, "Orígenes del presidencialismo. Un concepto americano del poder político", Confluencias, México, vol. I, núm. 3, 1996.

Diamond, Larry y Plattner , Marc F. (comps.), El resurgimiento global de la democracia, México, UNAM, Instituto de Investigaciones Sociales, 1996.

El Mercurio, Santiago de Chile (edición en línea 2011, 2012, 2013, 2014, 2015).

Faoro , Raymundo, Os donos do poder. Formação do patrónato político brasileiro, Sao Pablo, Editora Globo, 1998.

Fuentes , Carlos, La muerte de Artemio Cruz, México, Fondo de Cultura Económica, 1962.

Gutiérrez Martínez, Elia, El movimiento estudiantil secundario en Chile. Continuidades y cambios, México, UNAM, Facultad de Filosofía y Letras, tesis doctoral en pedagogía, 2017.

Habermas, Jürgen, Crisis de legitimación en el capitalismo tardio, Buenos Aires, Amorrortu, 1985.

Jocel yn-Hol t, Alfredo, "Todavía vivimos bajo una dictadura", El Mostrador, Santiago, 29 de marzo de 2001.

Linz, Juan J., La quiebra de las democracias, Madrid, Alianza, 1996.

Linz, Juan J. y Valenzuela , Arturo (eds.), The Failure of Presidential Democracy: The Case of Latin America, Baltimore-Londres, The John Hopkins University Press, 1993.

Loveman, Brian, The Constitution of Tyranny. Regimes of Exception in Spanish America, Pittsburgh, University of Pittsburgh Press, 1993.

Luhmann, Niklas, Cómo es posible el orden social, México, Herder Editores, 2010. 
Luhmann, Niklas, La sociedad de la sociedad, México, Herder-Universidad Iberoamericana Editores, 2007.

Luhmann, Niklas, Teoría política en Estado de bienestar, Madrid, Alianza, 1993.

Mainwaring, Scott y Shuga rt, Matthew, "Juan Linz: presidencialismo y democracia. Una revisión crítica", Desarrollo Económico. Revista de Ciencias Sociales, México, vol. 34, núm. 135, octubre-diciembre de 1994.

Mainwaring, Scott y Shugar t, Matthew (eds.), Presidentialism and Democracy in Latin America, Cambridge, Cambridge University Press, 1997.

Maquia velo, Nicolás, Discursos sobre la primera década de Tilo Livio, Madrid, Alianza, 2009.

Morlino , Leonardo, Cómo cambian los regímenes políticos, Madrid, Ediciones del Centro de Estudios Constitucionales, 1985.

Moulian , Tomás, Democracia y socialismo en Chile, Santiago, FLACSO, 1983.

Moulian , Tomás, "El Chile actual y su secreto", Chile '96. Análisis y opiniones, Santiago, FLACSO, 1997.

Moulian , Tomás, Chile actual, anatomía de un mito, Santiago, Editorial LOM, 1997.

O’Donnell, Guillermo, "Delegative Democracy”, Journal of Democracy, vol. 5, núm. 1, 1994.

O’Donnell , Guillermo, Contrapuntos, Barcelona, Paidós, 1997.

Pasquino, Gianfranco, voz "Formas de gobierno", en Bobbio, Norberto et al., Diccionario de política, México, Siglo XXI Editores, 1983.

Pereyra , Carlos, Sobre la democracia en México, México, Cal y Arena, 1990.

Programa de las Naciones Unidas para el Desarrollo, PNUD Chile, 2004, 2010, 2015, Desarrollo Humano en Chile. Tiempos de la politización, Chile.

Sar t ori, Giovanni, Ingeniería constitucional comparada. Una investigación de estructuras, incentivos y resultados, México, Fondo de Cultura Económica, 1996.

Schmitt , Carl, Teoría de la Constitución, México, Nacional, 1981. 
ScorZA, Manuel, Redoble por Rancas, Lima, PIESA-Edición Peruana, 1987.

SloterdiJK, Peter, Crítica de la razón cínica, Madrid, Siruela, 2007.

TEUBNER, Gunther, "Elementos materiales y reflexivos en el derecho moderno", en Bourdieu, Pierre y TEuBner, Gunther, La fuerza del derecho, Colombia, Siglo del Hombre Editores, 2002.

Teubner, Gunther, $O$ direito como sistema autopoiético, Lisboa, Edição da Fundação Calouste Gulbenkian, 1989.

VAlenZuela, Arturo, Presidencialismo y parlamentarismo en América Latina, México, Instituto Federal Electoral, 1998.

WeBer, Max, La sociología del derecho, México, UNAM, 1989.

WiLlKe, Helmut, Systemtheorie Entwickelter. Gesellschaften Dynamik und Riskanz moderner gesellschaftlicher Selbstorganisation, Deutschland, Juventa Verlag-Weinheim/München, 1993.

Wolf, Erick, Peasent Wars of the Twentieth Century, Nueva York, Harper and Row, 1969.

ZAMORANO FARÍAS, Raúl, Entre la teoría y la acción. Dilemas sobre la acción colectiva popular, Santiago de Chile: 1988-1992, México, Juan Pablos Editor, 2001.

ZAMORANO FARÍAS, Raúl, "Logiche di inclusione-esclusione politica nella società moderna (come la legge si rispetta, ma non obbedì)", Rivista Teoria del Diritto e dello Stato 3, Turín, Giappichelli Editore, 2003.

ZAMORANO FARÍAS, Raúl, Observando el orden social en México: el sistema de la política y el sistema del derecho, México, Juan Pablos Editor, 2017.

ZAPATA, Francisco, Ideología y política en América Latina, México, Colmex, 1990.

Zolo, Danilo, Il principato democratico. Per una teoria realistica della democracia, Milán, Feltrinelli Editore, 1992.

Fecha de recepción: 18 de marzo de 2017.

Fecha de dictamen: 10 de agosto de 2017. 